\title{
Determination of Free Fatty Acid by FT-NIR Spectroscopy in Esterification Reaction for Biodiesel Production
}

\author{
Djéssica Tatiana Raspe and Camila da Silva \\ Department of Technology, Maringá State University (UEM), 87506-370 Umuarama, PR, Brazil \\ Correspondence should be addressed to Camila da Silva; camiladasilva.eq@gmail.com
}

Received 26 December 2012; Revised 2 April 2013; Accepted 12 April 2013

Academic Editor: Johan E. Hustad

Copyright (C) 2013 D. T. Raspe and C. da Silva. This is an open access article distributed under the Creative Commons Attribution License, which permits unrestricted use, distribution, and reproduction in any medium, provided the original work is properly cited.

\begin{abstract}
This work reports the use of FT-NIR spectroscopy coupled with multivariate calibration to determine the percentage of free fatty acids (FFA) in samples obtained by the esterification of FFA in vegetable oils. The analytical method used as calibration matrix samples of the reaction medium of esterification of oleic acid in soybean oil in proportions of 0.3 to 40 wt $\%$ (by weight) of oleic acid obtained under different experimental conditions and utilized the partial least squares (PLS) regression. The efficiency of the method was tested to predict the content of FFA in reactions of esterification of oleic acid in soybean oil catalysed by KSF clay and Amberlyst 15 commercial resin, both in a batch mode. Good Correlations were observed between the FT-NIR/PLS method and the reference method (AOCS). The results confirm that FT-NIR spectroscopy, in combination with multivariate calibration, is a promising technique for monitoring esterification reaction for biodiesel production.
\end{abstract}

\section{Introduction}

The merits of biodiesel (fatty acid ethyl or methyl esters) obtained from vegetable oils or animal fats as an alternative to mineral diesel comprise a nontoxic, biodegradable, and a domestically produced and renewable source which is well documented in the literature $[1,2]$. Because of the well-known environmental and economical benefits, biodiesel fuel may be expected to be a good alternative to petroleum-based fuel [3] . The biodiesel production is generally accomplished in homogeneous [4-6] and heterogeneous [7-9] reaction systems at low pressures. Recently, the noncatalytic reaction, using alcohol under supercritical conditions at high temperatures and pressures, has also been investigated as an alternative method for fatty acid esters production [10-12].

Fatty acid, methyl or ethyl, esters can be usually obtained from free fatty acid (FFA) esterification reaction, through vegetable oils hydrolysis followed by the fatty acid esterification or from direct vegetable oils transesterification [13]. The importance of examining the esterification reaction in a more detailed manner is justified by the huge amount and variety of vegetable oils worldwide available for biodiesel production [14-16], which may have a high percentage of FFA making the conventional alkali-catalyzed transesterification impracticable, since for this process, the percentage of FFA is to be less than $0.5 \%[1,17,18]$. Recent studies propose to obtain esters in two reaction steps of substrates with high acidity, consisting of two approaches: (1) esterification of FFA and subsequent transesterification of triglycerides [19-22] or (2) hydrolysis of triglycerides, followed by esterification of fatty acids obtained [23-25].

According to AOCS [26], the acidity in vegetable oils can be determined by acid-base titration, using sodium hydroxide titrant and phenolphthalein as an indicator, such a method is commonly used because of simplicity of operation however, the method is slow, laborious; and lacks precision. In determining, large quantities of samples and reagents/solvents are consumed during operation [27-29]. The content of FFA can be determined by gas chromatography that involves complex steps of sample preparation and derivatization as the costs of internal standardization. Other methods involve techniques of high performance liquid chromatography [13] which eliminates the steps of derivatization; however, there is the high consumption of solvents used as mobile phase and the long time for analysis. A method that has been able to overcome such drawbacks 
is the FT-NIR spectroscopy, with the analytical procedure which provides rapid, direct (no pretreatment), reproducible, and moreover, the cost per analysis that is relatively low when compared to classical techniques $[30,31]$ and may be used in online monitoring of chemical reactions [32].

In this sense, the main objective of the present work is to investigate the application of spectroscopy FT-NIR for the quantitative determination of FFA in esterification reaction for biodiesel production.

\section{Materials and Methods}

2.1. Materials. Commercial refined soybean oil (Soya) and oleic acid (Sigma-Aldrich 99.9\%) were used as substrates without further treatment. In esterification reactions, ethanol (Merck 99.9\%) and as catalyst: KSF clay (Sigma-Aldrich) and Amberlyst 15 commercial resin (Supelco) were utilized. The characteristics of the catalysts are presented in the work of Zanette et al. [33]. In step titration of samples: solution of ethyl alcohol/ethyl ether 1:2 (v:v) (Vetec/Nuclear), $0.1 \mathrm{~N}$ sodium hydroxide (Nuclear), and phenolphthalein indicator (Nuclear) were used. All other reagents and solvents were of analytical grade.

2.2. Esterification Reactions of Oleic Acid in Soybean Oil. The samples obtained by esterification reaction were used for calibration and validation of the methodology. The esterification of oleic acid in soybean oil with ethanol in the presence of a heterogeneous catalyst (KSF clay and Amberlyst resin) was studied, and a synthetic sample of soybean oil with $40 \mathrm{wt} \%$ of oleic acid was utilized. For calibration and validation steps, different reactions were carried using different molar ratios of oleic acid to ethanol (from 1:10 to $1: 40$ ), temperature (from $50^{\circ} \mathrm{C}$ to $80^{\circ} \mathrm{C}$ ), and amounts of catalyst (from 2 to $20 \mathrm{wt} \%$ ) in order to obtain samples with different oleic acid contents.

The esterification reaction was carried out with magnetic stirrers in a batch reactor equipped with condenser and immersed in a temperature-controlled water bath. The oil was heated until the desired temperature was reached. At this point, ethanol and the catalyst were added to the oil, and the esterification reaction began. At the end of reaction, the catalyst was separated by centrifuged $(3000 \mathrm{rpm}$ for 10 minutes), and the ethanol and water were removed from the reaction mixture using a rotary evaporator.

2.3. FT-NIR Method. For the calibration of the FT-NIR method, FFA concentrations in samples from the reaction medium of esterification were determined by both FT-NIR and the conventional titration method by acid-base titration with $0.1 \mathrm{M} \mathrm{NaOH}$ in the presence of phenolphthalein. FFA content (FT-NIR and titration) was determined twice for each sample, and the average values are reported. The FTNIR absorbance spectra were acquired in the range from 700 to $2500 \mathrm{~nm}$ in spectrophotometer FT-NIR model N-200 (Büchi).

Sixty spectra were used in these procedures, which were divided into two sets of data by the NIRCal software. The first set contained 40 spectra which were used to create the calibration protocol by extracting from them the relevant information. The second set contained 20 spectra which were used in the validation of calibration. Spectral treatments were applied, and calibration models were constructed using the software NIRCal 4.01 (Büchi). Multivariate calibration was performed by partial least squares (PLS) regression in order to study the relationship between the reference data and the FT-NIR data. This was assessed by a leave-one-out crossvalidation procedure and optimized in terms of the appropriate number of factors and pretreatment by minimizing the root-mean-square error (RMSE) as in the following:

$$
\mathrm{RMSE}=\sqrt{\sum_{i=1}^{n} \frac{\left(y_{\mathrm{FT}-\mathrm{NIR}}-y_{\mathrm{REF}}\right)^{2}}{N}},
$$

where the terms "FT-NIR" and "REF" denote the predicted value and reference value, respectively. The relative standard error is designated as RMSEC (\%) for calibration and RMSEV (\%) for validation. The model that was finally adopted was that which led to the smallest possible RMSE value for a set of samples not previously used to construct it.

The calibration curve obtained is a mathematical algorithm that contains the necessary information to carry out the pretreatment of the obtained spectrum, more a linear function of Absorbance versus FFA content that can be used to predict the concentration of the chemical component of interest in samples of unknown composition using the instrumental response of them.

The predictive capability was tested against fourteen samples of reaction medium of esterification. The device outputs were compared with those obtained by the reference method [26] by means of linear correlation, using the software Statistica 6.0 (StatSoft Inc.). A prediction model based on the same test set was generated and evaluated via the rootmean-square error of prediction (RMSEP).

\section{Results and Discussion}

3.1. Calibration Model for FFA Content. Forty samples of esterification of oleic acid in soybean oil were used for the development of the calibration model for the FFA content. The FFA content in the samples ranged from $0.3 \mathrm{wt} \%$ to $45 \mathrm{wt} \%$. The calibration of the method adopted as criterion the acidity values reported in the literature for the vegetable oils used for the biodiesel production [13]. The pretreated FTNIR spectra utilized in the construction of the calibration curve as well the respective wavelength range analyzed are shown in Figure 1.

The calibration of the method was evaluated considering the correlation between the percentage of free fatty acids (FFA) predicted by FT-NIR and determined by the reference method [26]. In the chemometric treatment of data, the method of partial least squares (PLS) regression evaluated to the data for the spectrum obtained in the spectral region between 1000 and $2500 \mathrm{~nm}$. Spectra pretreatment was necessary to avoid baseline fluctuations several methods of pretreatment have been tested, and the results are summarized in Table 1. 
TABLE 1: Cross-validation and external validation results for the prediction of FFA content (\%) using different pretreatment methods.

\begin{tabular}{|c|c|c|c|}
\hline Parameter & $\begin{array}{l}\text { Baseline } \\
\text { correction }^{\text {a }}\end{array}$ & ${ }^{\mathrm{a}}+\mathrm{SG}$ smoothing ${ }^{\mathrm{b}}$ & ${ }^{b}+$ Derivative $^{c}$ \\
\hline PLS factors & 17 & 17 & 17 \\
\hline$R^{2}$ calibration & 0.819 & 0.8124 & 0.9487 \\
\hline$R^{2}$ validation & 0.966 & 0.9698 & 0.9407 \\
\hline RMSEC (\%) & 2.022 & 1.968 & 1.35 \\
\hline RMSEV (\%) & 3.706 & 2.685 & 1.68 \\
\hline
\end{tabular}

${ }^{a}$ Obtained using as reference the spectra without pretreatment.

${ }^{\mathrm{b}}$ Savitzky-Golay smoothing.

${ }^{c}$ First derivative obtained by the Savitzky-Golay method.

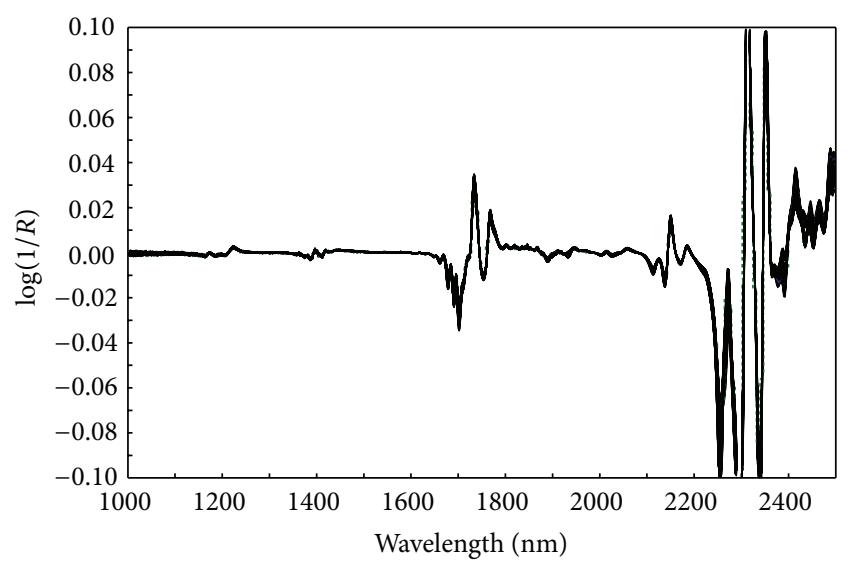

FIGURE 1: Pretreated FT-NIR spectra of samples of esterification medium.

The lowest RMSEV obtained was 1.35 and 1.68 using 17 (seventeen) PLS factors for calibration and validation of the method, respectively. The linear regression made between the points that represent the predicted content of FFA against the measured points was 0.9487 . In cross-validation test, this regression was 0.9407 .

Chang et al. [34] reported the application of PLS method and FT-NIR spectroscopy to monitor the enzymatic interesterification. The correlation found by these authors was 0.903 at $20^{\circ} \mathrm{C}$, and values of RMSEC and RMSEP was 1.096 and 1.827, respectively, using 5 (five) factors for the PLS method. Multivariate curve resolution-alternating least squares (MCR-ALS) methodology applied to near-infrared spectroscopy (NIR) data for the esterification reaction between glycerol and a mixture of caprylic and capric acids was reported by Blanco et al. [35]. The authors reported values of 3.7 and 6.1 for steps of calibration and prediction of methodology in concentration interval of 0.4 to 162 (mg KOH/g sample) for acid value. Zhang et al. [36] showed the application of FT-NIR spectroscopy in order to monitor the enzymatic interesterification process for butterfat modification using PLS method and values of 0.173 and 0.675 were reported for RMSEC and RMSEV, respectively. Blanco et al. [37] show the potential of near-infrared (NIR) spectroscopy for monitoring the esterification of stearic acid by glycerol

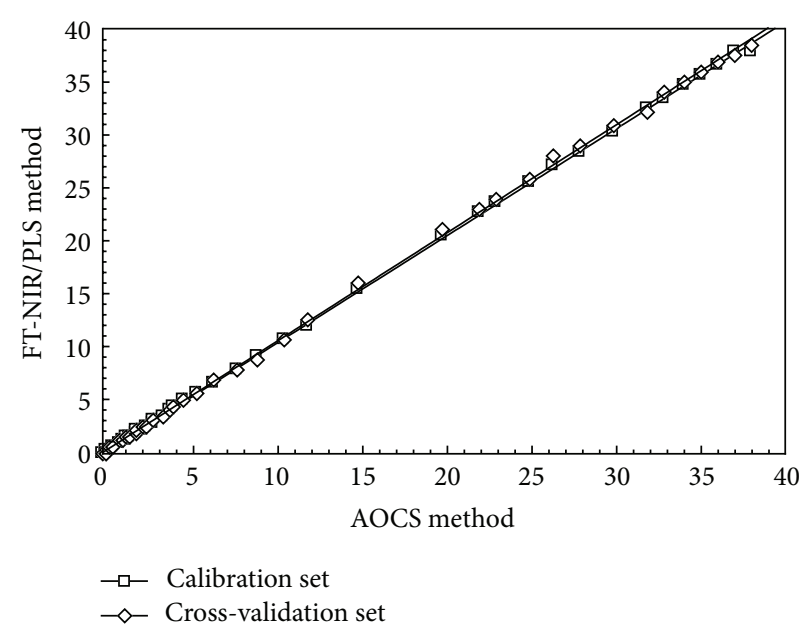

Figure 2: Correlation between the method of reference (AOCS, 1998) and FT-NIR/PLS for FFA content (wt\%) in samples of reaction medium of esterification ( $\square$ ), Calibration set; $(\diamond)$ cross-validation set.

constructed PLS models and reported relative standard error (RSEC and RSEV) of 2.1 and 6.7, respectively.

Figure 2 shows the performance of the model developed using PLS method to the experimental data. The results presented in Table 1 and Figure 2 demonstrated that the calibration models developed perform very well in the prediction of the FFA content.

3.2. Prediction Efficiency of FT-NIR/PLS Method for Monitoring Esterification Reactions. After determining the mathematical algorithm of prediction (linear function of the calibration curve more the data pretreatment condition), it was inserted into the prediction software of the FT-NIR equipment. Then, its predictive capability was tested in an independent dataset of reaction medium of esterification, and the FFA content was determined as the previously described methodology.

The output data were then inserted into the Statistica 6.0 software. In this independent dataset, the linear regression between the points that represents the reference methodology (AOCS, 1998) against the predicted by FT-NIR/PLS methodology was $0.99 \pm 0.05$ (Figure 3 ). The RMSEPs obtained for the results reported in Figure 3 were 1.15 and 1.07 for reaction with KSF and Amberlyst as catalysts, respectively.

According to our results obtained with the prediction of FFA content in the reaction medium of esterification from the independent set of samples, it was observed that both methodologies are well correlated and now, this methodology can be used routinely to predict the yields of esterification reaction for biodiesel production.

The use of ${ }^{1} \mathrm{H}$ NMR method for the quantification of FFA content during the esterification of oleic acid in methanol was reported by Satyarthi et al. [29] with high correlation (0.99) with this method and the titration method. Aryee et al. [28] evaluated the suitability of FT-IR method for the determination of FFA in fish oils for the production of 


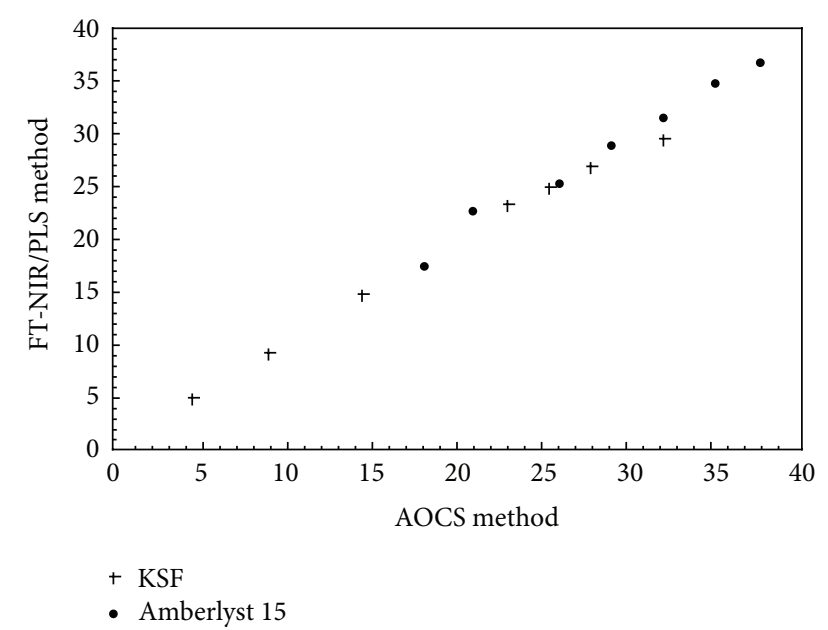

FIGURE 3: Comparison of FFA content determined by the reference method (AOCS, 1998) and predicted by the FT-NIR/PLS for samples of reaction medium of esterification with different catalysts.

biodiesel and reported a high correlation to the proposed methodology for FFA concentration from 0 to $6.5 \%$ by weight.

For the quantification of methyl esters in samples of transesterification reactions by NIR spectroscopy and PLS method, Baptista et al. [38] reported an $R^{2}$ prediction of 0.930 and RMSEP of $0.9 \%$, and Killners et al. [39] for on-line monitoring of the biodiesel production reported RMSEPs of 0.74 and 1.27 for the transesterification reaction carried out at $20^{\circ} \mathrm{C}$ and $55^{\circ} \mathrm{C}$, respectively.

\section{Conclusion}

This work reported experimental data for FT-NIR calibration models for prediction of the esterification yields for biodiesel production. Results demonstrate that FT-NIR spectroscopy is a valuable tool to predict the FFA content in samples of reaction medium of esterification, with errors similar to the maximum errors admitted by the reference method. The FT-NIR/PLS method shows RMSEP of about $1.1 \%$ and high correlation $(R>0.99)$ between the methodology developed and the reference method. The FT-NIR/PLS is nondestructive and requires a small amount of the sample. It can be used to monitor the esterification reaction of FFA to biodiesel.

\section{Acknowledgments}

The authors thank CNPq (472962/2009-4), CAPES (PRO$\mathrm{CAD}$ and ProEngenharias), and Maringá State University (UEM).

\section{References}

[1] H. Fukuda, A. Kondo, and H. Noda, "Biodiesel fuel production by transesterification of oils," Journal of Bioscience and Bioengineering, vol. 92, no. 5, pp. 405-416, 2001.
[2] R. Altin, S. Çetinkaya, and H. S. Yücesu, "Potential of using vegetable oil fuels as fuel for diesel engines," Energy Conversion and Management, vol. 42, no. 5, pp. 529-538, 2001.

[3] D. C. Grotta, A. Lopes, C. E. A. Furlani, R. P. Silva, G. N. Reis, and J. W. Cortez, "Biodiesel etílico filtrado de óleo residual de soja: desempenho de um trator agrícola na operação de gradagem," Acta Scientiarum Tecnhology, vol. 30, no. 2, pp. 135$138,2008$.

[4] D. De Oliveira, M. Di Luccio, C. Faccio et al., "Optimization of alkaline transesterification of soybean oil and castor oil for biodiesel production," Applied Biochemistry and Biotechnology Part A, vol. 122, no. 1-3, pp. 553-560, 2005.

[5] G. Vicente, M. Martínez, and J. Aracil, "Kinetics of Brassica carinata oil methanolysis," Energy and Fuels, vol. 20, no. 4, pp. 1722-1726, 2006.

[6] S. M. P. Meneghetti, M. R. Meneghetti, C. R. Wolf et al., "Biodiesel from castor oil: a comparison of ethanolysis versus methanolysis," Energy and Fuels, vol. 20, no. 5, pp. 2262-2265, 2006.

[7] G. S. Silva, D. Y. Inoue, G. Dors, A. Furigo Jr., and H. F. Castro, "Desempenho de diferentes lipases imobilizadas na síntese de biodiesel de óleo de palma," Acta Scientiarum Tecnhology, vol. 33, no. 2, pp. 197-203, 2011.

[8] S. Semwal, A. K. Arora, R. O. Badoni, and D. K. Tuli, "Biodiesel production using heterogeneous catalysts," Bioresource Technology, vol. 102, no. 3, pp. 2151-2161, 2011.

[9] A. P. S. Chouhan and A. K. Sarma, "Modern heterogeneous catalysts for biodiesel production: a comprehensive review," Renewable and Sustainable Energy Reviews, vol. 15, no. 9, pp. 43784399, 2011.

[10] T. Pinnarat and P. E. Savage, "Assessment of noncatalytic biodiesel synthesis using supercritical reaction conditions," Industrial and Engineering Chemistry Research, vol. 47, no. 18, pp. 6801$6808,2008$.

[11] D. Wen, H. Jiang, and K. Zhang, "Supercritical fluids technology for clean biofuel production," Progress in Natural Science, vol. 19, no. 3, pp. 273-284, 2009.

[12] C. Silva, G. Borges, F. Castilhos, J. V. Oliveira, and L. Cardozo Filho, "Continuous production of fatty acid ethyl esters from soybean oil at supercritical conditions," Acta Scientiarum Tecnhology, vol. 34, no. 2, pp. 185-192, 2012.

[13] G. Knothe, J. V. Gerpen, and J. Krahl, The Biodiesel Handbook, AOCS Press, Champaign, Ill, USA, 2005.

[14] M. K. Lam, K. T. Lee, and A. R. Mohamed, "Homogeneous, heterogeneous and enzymatic catalysis for transesterification of high free fatty acid oil (waste cooking oil) to biodiesel: a review," Biotechnology Advances, vol. 28, no. 4, pp. 500-518, 2010.

[15] P. Nakpong and S. Wootthikanokkhan, "High free fatty acid coconut oil as a potential feedstock for biodiesel production in Thailand," Renewable Energy, vol. 35, no. 8, pp. 1682-1687, 2010.

[16] A. Hayyan, M. Z. Alam, M. E. S. Mirghani et al., "Reduction of high content of free fatty acid in sludge palm oil via acid catalyst for biodiesel production," Fuel Processing Technology, vol. 92, no. 5, pp. 920-924, 2011.

[17] F. Ma and M. Hanna, "Biodiesel production: a review," Biresource Technology, vol. 70, no. 1, pp. 1-15, 1999.

[18] A. P. Vyas, J. L. Verma, and N. Subrahmanyam, "A review on FAME production processes," Fuel, vol. 89, no. 1, pp. 1-9, 2010.

[19] M. Berrios, M. A. Martín, A. F. Chica, and A. Martín, "Study of esterification and transesterification in biodiesel production from used frying oils in a closed system," Chemical Engineering Journal, vol. 160, no. 2, pp. 473-479, 2010. 
[20] K. Srilatha, T. Issariyakul, N. Lingaiah, P. S. Sai Prasad, J. Kozinski, and A. K. Dalai, "Efficient esterification and transesterification of used cooking oil using 12-tungstophosphoric acid (TPA) $/ \mathrm{Nb}_{2} \mathrm{O}_{5}$ catalyst," Energy and Fuels, vol. 24, no. 9, pp. 4748-4755, 2010.

[21] L. T. Thanh, K. Okitsu, Y. Sadanaga, N. Takenaka, Y. Maeda, and H. Bandow, "A two-step continuous ultrasound assisted production of biodiesel fuel from waste cooking oils: a practical and economical approach to produce high quality biodiesel fuel," Bioresource Technology, vol. 101, no. 14, pp. 5394-5401, 2010.

[22] G. Corro, N. Tellez, T. Jimenez, A. Tapia, F. Banuelos, and O. Vazquez-Cuchillo, "Biodiesel from waste frying oil. Two step process using acidified $\mathrm{SiO}_{2}$ for esterification step," Catalysis Today, vol. 166, no. 1, pp. 116-122, 2011.

[23] S. Gan, H. K. Ng, C. W. Ooi, N. O. Motala, and M. A. F. Ismail, "Ferric sulphate catalysed esterification of free fatty acids in waste cooking oil," Bioresource Technology, vol. 101, no. 19, pp. 7338-7343, 2010.

[24] L. L. L. Rocha, A. L. D. Ramos, N. R. A. Filho, N. C. Furtado, C. A. Taft, and D. A. G. Aranda, "Production of biodiesel by a two-step niobium oxide catalyzed hydrolysis and esterification," Letters in Organic Chemistry, vol. 7, no. 7, pp. 571-578, 2010.

[25] J. S. de Sousa, E. D. Cavalcanti-Oliveira, D. A. G. Aranda, and D. M. G. Freire, "Application of lipase from the physic nut (Jatropha curcas L.) to a new hybrid (enzyme/chemical) hydroesterification process for biodiesel production," Journal of Molecular Catalysis B, vol. 65, no. 1-4, pp. 133-137, 2010.

[26] R. E. Walker, Ed., Official Methods and Recommended Practices of the American Oil Chemists' Society (Method AOCS Cd 3d-63), 5th edition, 1998.

[27] A. F. C. Pereira, M. J. C. Pontes, F. F. Gambarra Neto, S. R. B. Santos, R. K. H. Galvão, and M. C. U. Araújo, "NIR spectrometric determination of quality parameters in vegetable oils using iPLS and variable selection," Food Research International, vol. 41, no. 4, pp. 341-348, 2008.

[28] A. N. A. Aryee, F. R. van de Voort, and B. K. Simpson, "FTIR determination of free fatty acids in fish oils intended for biodiesel production," Process Biochemistry, vol. 44, no. 4, pp. 401-405, 2009.

[29] J. K. Satyarthi, D. Srinivas, and P. Ratnasamy, "Estimation of free fatty acid content in oils, fats, and biodiesel by $1 \mathrm{H}$ NMR spectroscopy," Energy and Fuels, vol. 23, no. 4, pp. 2273-2277, 2009.

[30] H. Cen and Y. He, "Theory and application of near infrared reflectance spectroscopy in determination of food quality," Trends in Food Science and Technology, vol. 18, no. 2, pp. 72-83, 2007.

[31] A. Muller and H. Steinhart, "Recent developments in instrumental analysis for food quality," Food Chemistry, vol. 101, no. 3, pp. 1136-1144, 2007.

[32] M. Garrido, F. X. Rius, and M. S. Larrechi, "Multivariate curve resolution-alternating least squares (MCR-ALS) applied to spectroscopic data from monitoring chemical reactions processes," Analytical and Bioanalytical Chemistry, vol. 390, no. 8, pp. 2059-2066, 2008.

[33] A. F. Zanette, R. A. Barella, S. B. C. Pergher et al., "Screening, optimization and kinetics of Jatropha curcas oil transesterification with heterogeneous catalysts," Renewable Energy, vol. 36, no. 2, pp. 726-731, 2011.
[34] T. Chang, X. Lai, H. Zhang, I. Søndergaard, and X. Xu, "Monitoring lipase-catalyzed interesterification for bulky fat modification with FT-IR/NIR spectroscopy," Journal of Agricultural and Food Chemistry, vol. 53, no. 26, pp. 9841-9847, 2005.

[35] M. Blanco, M. Castillo, A. Peinado, and R. Beneyto, "Application of multivariate curve resolution to chemical process control of an esterification reaction monitored by near-infrared spectroscopy," Applied Spectroscopy, vol. 60, no. 6, pp. 641-647, 2006.

[36] H. Zhang, H. Mu, and X. Xu, "Monitoring lipase-catalyzed butterfat interesterification with rapeseed oil by Fourier transform near-infrared spectroscopy," Analytical and Bioanalytical Chemistry, vol. 386, no. 6, pp. 1889-1897, 2006.

[37] M. Blanco, D. Zamora, M. Mir, and R. Mulero, "Study of the lipase-catalyzed esterification of stearic acid by glycerol using in-line near-infrared spectroscopy," Industrial and Engineering Chemistry Research, vol. 48, no. 15, pp. 6957-6960, 2009.

[38] P. Baptista, P. Felizardo, J. C. Menezes, and M. J. N. Correia, "Multivariate near infrared spectroscopy models for predicting the methyl esters content in biodiesel," Analytica Chimica Acta, vol. 607, no. 2, pp. 153-159, 2008.

[39] M. H. N. Killners, J. J. R. Rohwedder, and C. Pasquini, "A PLS regression model using NIR spectroscopy for on-line monitoring of the biodiesel production reaction," Fuel, vol. 90, no. 11, pp. 3268-3273, 2011. 


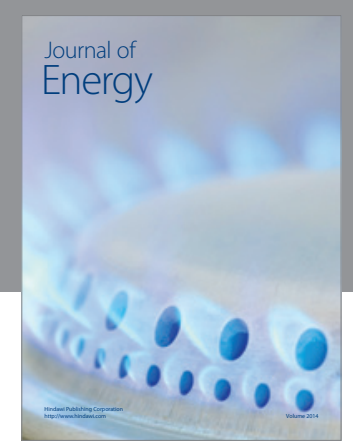

Journal of

Industrial Engineering
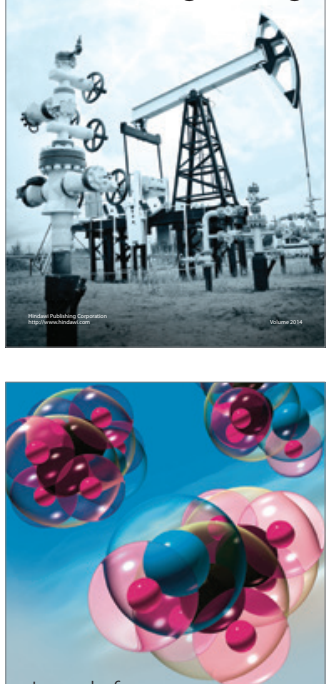

Fuels
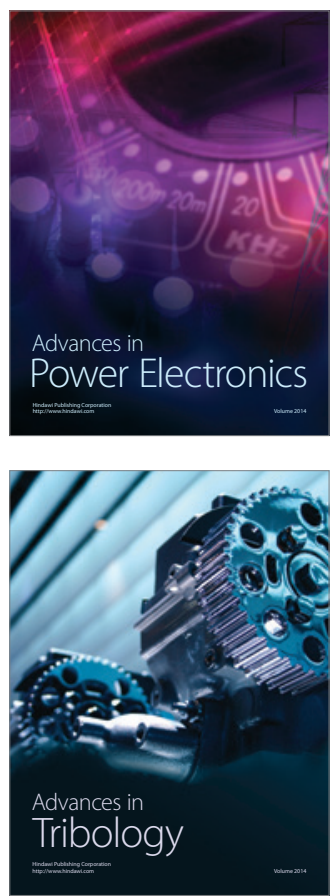

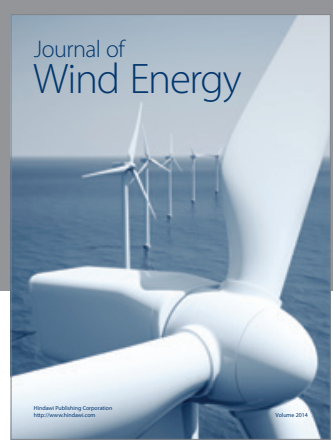

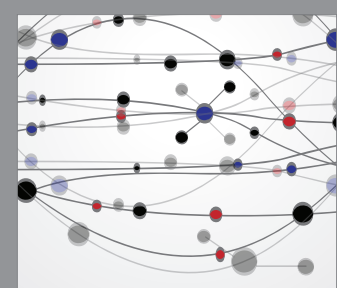

The Scientific World Journal

Submit your manuscripts at http://www.hindawi.com

Journal of

Structures
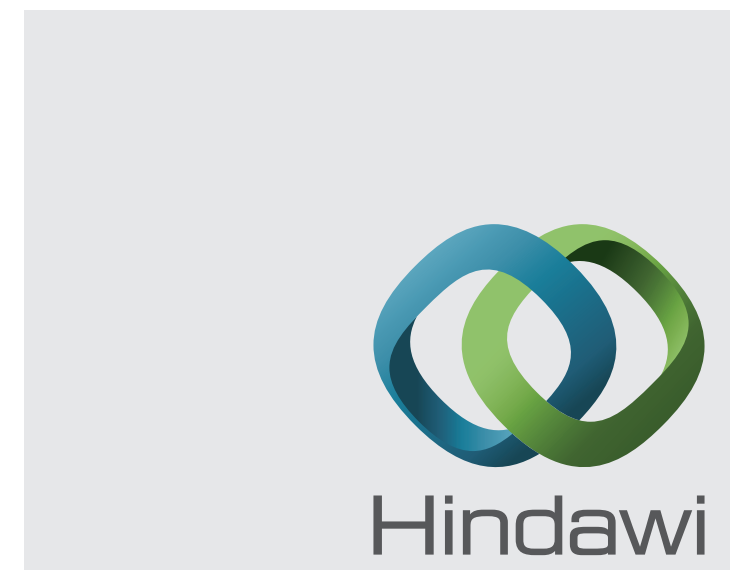

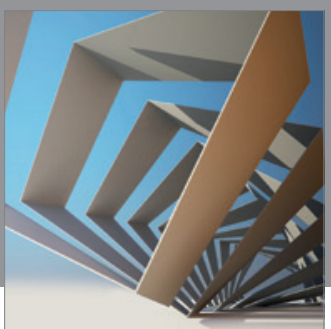

Rotating

Machinery
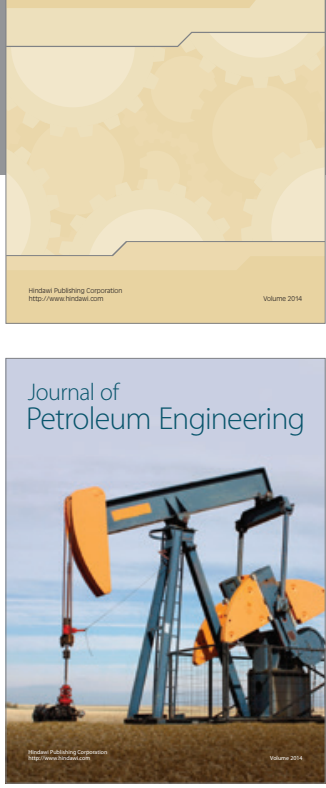

Journal of

Solar Energy
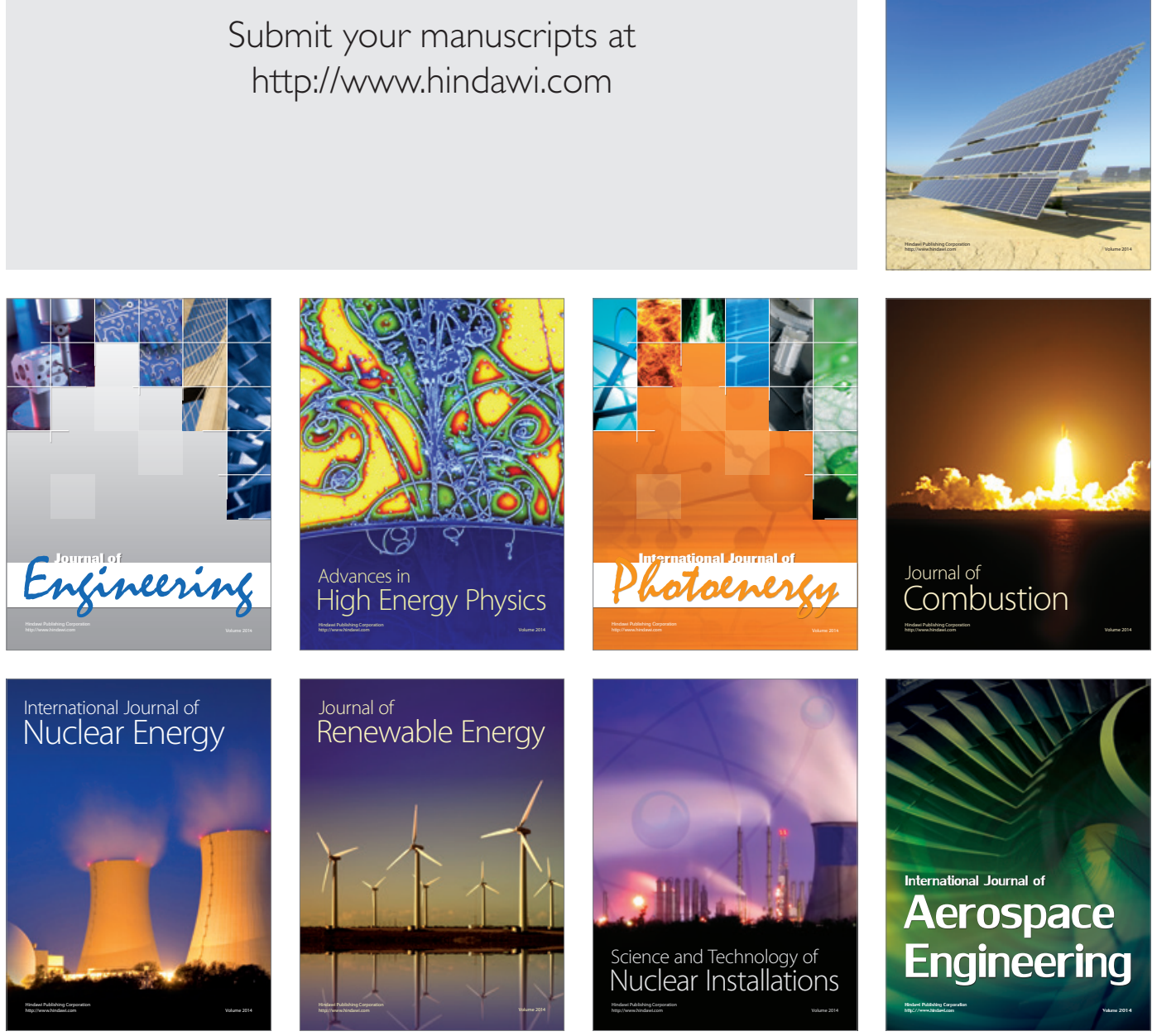